\title{
The composition and function of ethical committees
}

\author{
William W May University of Southern California
}

In this paper the need for review (ethical) committees is elaborated to include a discussion of their composition and function. In some institutions more than one such committee may be set up, a departmental ethical committee and one which studies the projects of all the departments concerned. By considering proposed research before it is started patients or volunteers are protected from injury, discomfort, and inconvenience, and the scientific validity of a clinical experiment can be scrutinized. A list of possible criteria for the work of ethical committees is given.

Ten years ago, in the Declaration of Helsinki, the World Medical Association undertook the formulation of a code by which clinical research with human beings could be regulated. ${ }^{1}$ The Declaration was an attempt to approach the subject in a way that would balance society's needs for the advancement of medical science against the rights of human subjects - patients and volunteers. Society demands the highest standard of medical care together with the protection of the patient against undue risk in experimentation and the preservation of his personal integrity. In the intervening years, 'clinical research' the term used in the United Kingdom, or 'experimentation with human subjects', as it is more commonly known in the United States, has been the subject of intense scrutiny by physicians, scientists, lawyers, theologians, moral philosophers, and sociologists. Published reports of conferences and symposia, a large collection of manuscripts and edited collections of essays, and endless articles in professional journals bear witness to the complexity of the subject and the careful attention that has been directed to it. ${ }^{2}$ In the face of so much effort why does the subject continue to command so much attention? The answer is to be found partly in the fact that the Declaration of Helsinki identified the two major interests to be served, the health of the people and the rights of the individual patient or volunteer, but did not resolve the issues of competing rights and values which the two interests represent. ${ }^{3}$ Also there is no agreement about what is ethically permissible for specific types of research and particular classes of subjects. Finally, effective and acceptable review processes have not yet been developed.

Certainly, considerable progress has been made in the decade since Helsinki in sharpening the issues raised by clinical research and in defining the rights and interests of all those concerned and in establishing review procedures. Even though important disagreements remain about specific interpretations and applications, the continuous probing on informed consent, the benefit-risk ratio, the distinction between therapeutic and non-therapeutic intervention, ${ }^{4}$ the unique problems of special groups as subjects of research, ${ }^{5}$ and the necessity for review by professional equals has resulted in a loosely structured ethical framework within which clinical research is assessed.

\section{The review procedure}

In this paper I wish to draw attention to two areas of great importance which have not been scrutinized as closely as certain others. I will in particular consider the ethical significance of the structure of the review procedure and of the scientific dimensions of the experimental design. These two areas of ethical criticism have not been wholly neglected; indeed the research committees in the United States and the ethical committees in the United Kingdom are the results. It is in the prior review process that the tensions and conflicts between societal needs and individual rights are resolved, and if those processes are faulty or inadequate, ethically dubious experimentation will continue. ${ }^{\circ}$

The primary concern should be to establish an effective review procedure, but, most importantly, we must ensure that members of review committees do not proceed in such a way that research is stifled through cumbersome structures or a policing mentality that will poison the atmosphere in the research hospitals. I wholly support the position declared by the Royal College of Physicians Committee on the Supervision of The Ethics of Clinical Research Investigation in Institutions when it says, 'If advances in medical treatment are to continue so must clinical research investigation ... ${ }^{7}$ It is a well established fact that we should not have had the developments we already have in medicine without clinical research. It is also true that the public wants medical advances, especially in those areas of disease, such as cancer and heart disease, where the greatest element of risk to subjects of clinical research exists. There is no question that the public interest is served by continuing in-

$$
\text { (t) }
$$

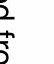


vestigation of new drugs and new medical procedures.

The primary guarantee of protection of subjects against needless risk and abuse is in the review before the work is undertaken. Monitoring research in progress has been suggested as necessary to prevent unapproved changes in experimental design, the manipulation of subjects to obtain consent, and the abuse of patients through improper treatment when difficulties occur during testing a procedure or a drug. ${ }^{8}$ Review after the event with the possibility of sanctions has proved to be highly suspect if not inadequate. ${ }^{9}$ Journal editors have a part in these checks and balances, but, despite important steps to develop and implement editorial policies vis $a$ vis unethical research, are subject to the obvious limitations of disagreement over what is unethical and concerned over charges of censorship. ${ }^{10}$ Thus, despite its inadequacies, review before a clinical experiment is begun may be the most useful way of defining the limits of any such trial and most acceptable to research workers. In fact it is the only stage at which the subject can be protected against needless risk of injury, discomfort, or inconvenience.

Although we have come a long way in the development of the structure of research committees in the United States and ethical committees in the United Kingdom, it is my contention that there are still major flaws in their organization. ${ }^{11} \mathrm{Al}$ though the sensitivity of the medical-scientific community to ethical problems with clinical research has been intensified, it is my further contention that the ethical significance of the adherence, or lack of adherence, to what I will call the canons of scientific methodology permits experimentation with human subjects of a dubious if not objectionable quality to proceed.

\section{The structure of review or ethical committees}

The structure of review committees varies greatly between the United States and the United Kingdom, but it also varies considerably within each nation. Although uniformity of pattern may not be a desirable or necessary goal, comparisons of existing patterns suggest some factors to be considered.

\section{RELATION BETWEEN THE SCIENTIFIC AND ETHICAL REVIEW}

The suggestion that the scientific and ethical review should be a related, if not a unified, process is based on an understanding that the adequacy of the scientific design is an ethical issue and that many of the ethical issues in experimentation have scientific dimensions. ${ }^{12}$ Some institutions have in fact created separate scientific committees and ethical committees with separate jurisdictions. Separation may, however, indicate a false dichotomy between the scientific and ethical aspects of clinical research, or, if the relationship is understood, it may lead to duplication by two committees. In some instances, the scientific review is understood to be the responsibility of the particular department in $\bar{\delta}$ which the research is being done, and the hospital committee reviews only the 'ethical issue', such as $\stackrel{\vec{f}}{\rightarrow}$ informed consent. In such a situation it is clear that $\bar{O}$ the understanding of what constitute the ethical $\frac{D}{\sigma}$ aspects of experimentation is too restrictive. Some $\frac{\bar{D}}{\square}$ argue that only fellow specialists can fully appreciate $\frac{\mathbb{Q}}{Q}$ a highly technical application for a grant and that o Federal review boards in the United States or Medical Research Council boards in the United Kingdom should perform the necessary scientific $\overrightarrow{\vec{\omega}}$

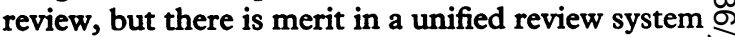
with all issues being considered and weighed $\overline{3}$ together. Failing unification, provision should be $\stackrel{\Phi}{-}$ made for cross-committee representation to ensure that an artificial separation between scientific $\underset{\omega}{N}$ and ethical does not permit some important 0 questions to go unraised.

DEPARTMENTAL AND HOSPITAL ETHICAL COMMITTEES

Opinion is almost unanimous on the importance of $\vec{\varphi}$ having representatives from all departments of a hospital on whatever type of committee is set up, and some commentators even discuss the desirability of membership from outside the institution. Some committees are so small that by definition $\stackrel{2}{\circ}$ they are not representative. In at least one instance, $\stackrel{\varnothing}{\varrho}$ the essential review of a proposed experiment is $\vec{\overrightarrow{ }}$ done by members of the discipline concerned, with 3 a wider review on ethical issues only if they request $\supsetneq$ one. In that institution, no problems had been referred beyond the departmental committee to a higher committee in the two years in which the $\underset{\mathbb{}}{\widetilde{T}}$ system operated. One argument for a small, speciali- $\bar{T}$ zed committee is that only those with the necessary scientific expertise, defined narrowly as those in a $\delta$ specialty, will have sufficient understanding to

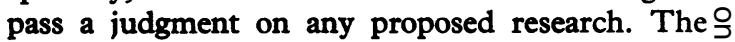
problem that then arises is that departmental $)$ review is open to all of the subtle pressures of position and power that affect interactions in small $\tilde{N}$ groups.

The pattern on review committees should be $\tilde{O}$ broad enough to ensure against any possibility that $\mathrm{\omega}_{\mathrm{N}}$ investigators become their own reviewers. Even in large departments, strong individuals or smallo groups wield tremendous power over policies and $\overparen{\Phi}$ procedures. Also, a consensus on what is appropriate $\stackrel{\oplus}{+}$ or ethical research practice develops within groups 0 and a self-selection process operates in choosing $\stackrel{P}{\circ}$ members. The dangers are obvious of an ingrown, $\stackrel{\odot}{\stackrel{D}{~}}$ narrow perspective developing in a department $\stackrel{\circ}{\alpha}$ which in many ways constitutes a research group. If the whole idea of review committees is taken seriously then the process must be framed in such응 a way that at the very least there is a true institution- 
al review. ${ }^{13}$ Moreover, if public confidence is to be maintained, the appearance as well as the fact of a rigorous, thorough review of clinical research must be present. In appearance, at least, some institutions fall short of the mark.

INCLUSION OF LAY MEMBERS ON ETHICAL COMMITTEES The inclusion of lay members on ethical committees has progressed further in the United States than it has in the United Kingdom, mainly because there has been more public criticism of experimentation in the United States than in the United Kingdom. Arguments against having lay members include assertions that they will not be able to understand the complexity of scientific experimentation, fears that they will not appreciate the benefits of clinical research and therefore act in an obstructionist fashion, and that committees should be as small as possible. Although due care needs to be exercised in the selection of lay members, I would argue that their potential contributions outweigh the objections. ${ }^{14}$

The lay member may serve to broaden the perspectives and values which inform the review procedure, and add to those of the medical members of the committee on the ethics of a project. The lay member may be able to bring a perspective which represents that of the community to the debate over what is appropriate and legitimate clinical investigation. Certainly the inclusion of lay members may complicate an already involved process which is seen by many researchers as already too cumbersome and lengthy, but it does not follow that the inclusion of lay members will necessarily cause further delays. Indeed, the complexity of the review and the time involved is not directly related to the size of the committee.

The lay member may also serve a useful function where written consent forms are required in ensuring that intricate procedures are described in language which the subject can understand. (Written consent forms tend to be the rule in the United States and the exception in the United Kingdom.) Serious questions have been raised about the process of obtaining informed consent, whether written or oral, and the lay member may be a useful observer where problems persist. ${ }^{15}$

Finally, the lay member may perform a valuable service in interpreting the nature and importance of clinical research to the public. Federal and State legislative hearings and much publicized questionable experiments in the United States have led to a higher degree of public awareness and concern than is apparent in the United Kingdom. However, the existence of patients' associations, some publications on abuses in clinical research, the formation of ethical committees, and formal statements by committees within the medical profession attest to the existence of real concern and potential pressures for legislation similar to that in the United States. In both countries, the interest in maintaining effective control of the review function at the local institutional level, which I share, can best be served by ensuring that clinical research and the review process are understood and accepted by the public. The appearance of openness is as important as the fact of openness, and the inclusion of lay members on ethical committees presents a different image than does a structure composed wholly of medical professionals.

\section{LAY PROFESSIONAL REPRESENTATIVES}

The composition of review committees goes beyond the question of including 'lay members' and ensuring that committees are representative of a whole institution. Arguments are strong for including a nurse, a statistician, and a lawyer. Several committees in the United Kingdom include a nurse who plays a valuable role in interpreting clinical investigations to the nursing staff and their professional concern to the physicians. The nurse is often the first professional contact with patient-subjects in hospital and also serves as the witness in the process of obtaining consent.

The statistician can play an invaluable role, and it is somewhat surprising that that profession is not universally represented on committees. Although the specific problems associated with statistical validity will be discussed below, it appears to be the case that one of the most serious ethical problems in clinical research is that of placing subjects at the risk of injury, discomfort, or inconvenience in experiments where there are too few subjects for valid results, too many subjects for the point to be established, or an improperly designed random or double-blind procedure.

Lawyers serve on some review committees, and where they do, they play an important role in defining the current status of the law on the rights of particular classes of subjects, eg, children and fetuses, and they help to clarify the liability of the physician-experimenter in various situations.

One suggestion made for the future is that a socio-legal-ethical professional person should be trained who would represent a variety of interests on the review committee. Although the cost of training and employing such a professional might present difficulties, the suggestion is valuable and might prove workable, especially for groups of institutions in metropolitan areas. ${ }^{16}$

\section{SCRUTINY OF THE EXPERIMENTAL DESIGN}

I have difficulty in deciding whether it is foolhardy or presumptuous for a non-scientifically trained, non-medical observer to question the adequacy of experimental design. One might assume that there are standardized, accepted canons of scientific methodology that are applied rigorously to all scientific experimentation, clinical research included. One might further assume that in the normal 
process of the review of experimental protocols, the extent to which the experimenter adheres to the canons of scientific methodology are carefully assessed. Unfortunately, neither assumption appears warranted. A poorly designed or poorly conceived experiment is unethical by definition and should not be permitted. Further it is the responsibility of the review committee to ensure that the conception and design meet the accepted canons of scientific method because we are dealing with experimentation that may not be for the individual subject's direct benefit. The ethical justification for such experimentation, which is outside the pure physician-patient relationship, is based on a judgment that in certain circumstances it is legitimate to put a subject at risk, with his or her consent, because of the overriding need of society for progress in combating certain diseases. The argument is very involved, there is considerable variation and disagreement, but the consensus of opinion is that experimentation on human subjects is justified. At the same time, there is continuing and growing concern about particular classes of subjects, eg, children, fetuses, pregnant women, prisoners, patients, minority groups, and the mentally handicapped. These groups make up a very large part of the total population available for clinical research, and arguments are put forward with increasing frequency about excluding one or another from any experiment that is not potentially of direct therapeutic benefit. In Britain, the legal position is that children are not fit subjects for experimentation; in the United States the position varies from state to state.

Clinical research has long been justified or approved in principle, but today approval is being challenged and the conditions under which the research may continue is being circumscribed. Approval has been given with the knowledge that there is some risk of the violating the rights and integrity of the individual ${ }^{17}$, especially as the reality of truly informed consent is so seriously questioned. A poorly designed or poorly conceived experiment runs a great risk by its very structure of producing results that are invalid. Subjects of such experiments are needlessly put in jeopardy, as every precaution has not been taken to protect them against unnecessary risk, and the experiment is therefore unethical.

Perhaps the best illustration of this issue is given by Gifford and Feinstein in a review of the adequacy of the methodology of $\mathbf{3 2}$ carefully chosen studies of anticoagulant therapy for acute myocardial infarction. ${ }^{18}$ The article is important because it deals with a '... series of eight methodological standards that would be generally regarded as scientific necessities for ensuring comparability of treated patients in a clinical investigation of therapy.... The critical importance of the assessment by Gifford and Feinstein in demonstrating the necessity of ensuring that the experimental design is thoroughly examined is shown in some of their findings about the degree of adherence to the basic canons of scientific methodology. The eight methodological standards they use to establish comparability are the diagnostic criteria for myocardial infarction, controls, coordination between centres if the work is being $\stackrel{\vec{D}}{\stackrel{5}{+}}$ carried out at more than one, random allocation, $\bar{g}$ diagnostic criteria for thromboembolism, stratified $\frac{0}{\bar{t}}$ prognostic correlation double-blind procedure, the $\frac{\bar{p}}{7}$ number of cases, and therapeutic conclusions. Some $\stackrel{\mathbb{Q}}{\Omega}$ of the authors' most striking conclusions include a judgment that only 25 per cent of the experiments $\overrightarrow{ }$ .. . contain a satisfactory statement of the evidence used for making a clinical diagnosis of myocardial $\vec{\omega}$ infarction'. Moreover, one-third of the papers stated no criteria at all. A high proportion, 72 per cent, used rigorous controls, but the apparent lack of controls in the other 28 per cent seriously quali- $-\overrightarrow{-}$ fies their validity and very likely renders them useless. The authors found that only 12 per cent $O$ of the studies used random allocation and only one study out of the entire 32 used some double-blind $\rightarrow$ procedure. In the face of what we know about the placebo effect and the unconscious as well as $\vec{\oplus}$ conscious pressures that affect the judgment of research workers in the selection of patients as subjects for alternative treatments, the results of the analysis by Gifford and Feinstein on random allocation and double-blind trials lay tremendous emphasis on the need for close examination of the scientific design of experiments on human subjects. $\stackrel{\mathbb{Q}}{\varrho}$ According to these authors, the use of anti- $\overrightarrow{\overrightarrow{0}}$ coagulant therapy for myocardial infarction has 3 been a matter of considerable debate; their report indicates that extensive experimentation has not? resolved the issue because of failure in scientific methodology. If review committees were to analyze experimental protocols in terms of established standards of methodology, the pace of scientific progress would increase, and subjects would not $\delta$ be put at risk unnecessarily.

Chalmers, in a paper discussing specifically the $\frac{0}{5}$ ethics of randomization, considers the history of $>$ experimentation on portavacal shunt surgery in patients with cirrhosis. He points out that when N controlled studies were finally done on patients whose varices had not yet bled, '... combined 0 survival data from all three of these groups indicate $N$ that the operation actually shortens rather than prolongs life ...'19 One of the most importanto points to emerge from Chalmers' assessment is that procedures appear to become established as reliable? and effective treatments on the basis of reports of 0 positive results in uncontrolled experiments.

Once a positive attitude has been adopted by the medical community toward a specific treatment, it becomes less likely that controlled research will beo done and patients may receive unnecessary or even harmful treatment. It should be noted that at leasto some of the reports on portavacal shunts were from 
physicians treating patients and not from clinical investigations. This presents a complex problem of how to deal with therapy as experimentation. In many cases there is no prior review because a research design has not been formulated. Even so, reports were published in scientific journals.

There are still other examples of poorly conceived experiments that we could cite. Moore's commentary on the unfortunate history of research with the cancer cure Krebiozen focuses precisely on breaches in scientific method. ${ }^{20}$ As in the case of the studies on myocardial infarction, the time frame was many years and involved many subjects. Shaw and Chalmers, in assessing experimentation in the framework of the Veterans Administration in the United States, comment that the results of many experiments outside the Veterans Administration have been diminished if not rendered useless due to lack of randomization. ${ }^{21}$ In my own institution, we approved an experiment in spite of the fact that perhaps over 20000 subjects had been tested elsewhere in similar experiments because a Federal agency had declared that methodology had been inadequate and the results were not conclusive.

If evidence of the critical importance of adherence to the canons of scientific methodology is so readily available, why are not all research proposals rigorously examined in this context? There are several reasons. Part of the explanation is that a false dichotomy exists between science and ethics in some places, and so scientific methodology has not been a major concern for review committees. There is no doubt also that demands on the time of committee members and the necessary priority that has been given to the major, recurrent ethical issues cited earlier. In such a situation, the easiest way out is to rely on the individual researcher or his department to ensure that what are understood to be the basic tenets of scientific investigation will be followed.

My own argument is that review committees should specify for their own use and for research workers in their institutions the basic elements of experimental design that will be reviewed. In stressing the importance of scientific methodology in designing ethically defensible studies, it is important to emphasize the clinical setting of the scientific application. Gifford and Feinstein summarize it well when they say,

'As clinicians and statisticians collaborate in planning future research projects, an important point to be recognized is that treatment is an act of clinical medicine, and that valid statistical inferences must be based on this clinical context; accordingly, the critical features for scientific design for therapeutic experiments must be clinical and not merely statistical.'22

Perhaps what is needed is a list of basic items that the hospital review committee, the departmental committee, and the individual research worker might find useful. Although my suggestions will need refinement and expansion, and it must be recognized that flexibility is required in their interpretation. I would venture the following criteria for inclusion on such a list.

\section{Criteria for evaluating proposed research}

SCIENTIFIC VALIDITY

It must be clear that scientific, reproducible observations can be made. ${ }^{23}$

\section{CONTROLS}

It is essential to have properly controlled studies if there is to be certainty about the precise findings. There is some disagreement over whether pilot studies on up to Io subjects can be done before controls are introduced, but within the policy adopted by any institution controls should be used. ${ }^{24}$

\section{RANDOMIZATION}

Most commentators agree that randomization is an essential part of a well designed experiment. ${ }^{25}$

\section{DOUBLE-BLIND TRIALS}

There are strong opinions to be found for and against double-blind trials. I should like to insist on double-blind trials at some stage in testing procedures and drugs if a 'fail-safe' process is built in for a physician not involved in the trials to check results and to be prepared to intervene medically where necessary. ${ }^{26}$

\section{PLACEBOS}

The use of placebos appears warranted if no known viable alternative treatment or drug to the one being tested is available. It may be necessary in a triple-blind experiment. There are those who seriously oppose the use of placebos in experiments involving patients. ${ }^{27}$

\section{COMPREHENSIVENESS OF EXPERIMENT}

Computer analysis permits the testing of many rather than a few variables in a simplified system. Some unnecessary use of subjects could be avoided with more comprehensive planning and the use of specimens. ${ }^{28}$

\section{DURATION OF EXPERIMENT}

The emphasis on the clinical nature of experimentation with human subjects requires careful calculation whether extensive testing will interfere with treatment. ${ }^{20}$

\section{References and notes}

${ }^{1}$ See text in Katz, Jay (1972). Experimentation with human subjects, pp 312-313, Russell Sage Foundation, New York. 
${ }^{2}$ For the most complete resource book on experimentation with human subjects, see Katz, ibid. For an introduction to all of the major issues in experimentation, see Ethical aspects of experimentation with human subjects (1969). 98 Daedalus. Ladimer, Irving and Newman, Roger W (1963). editors of Clinical Investigation in Medicine: Legal, Ethical and Moral Aspects. Boston: Law-Medicine Research Institute, Boston University, and Ladimer, Irving, editor 'New Dimensions in Legal and Ethical Concepts for Human Research' (1970). Annals of the New York Academy of Sciences, 169, 293-593. For an important analysis by a physician whose commentary has been crucial, see Beecher, Henry K (1970). Research and the Individual: Human Studies. Boston: Little, Brown and Company. For an up-to-date bibliography see Bibliography of Society, Ethics, and the Life Sciences (1974). A Hastings Center publication, Institute of Society, Ethics and the Life Sciences. For theological perspectives on the issues involved in experimentation see Campbell, A V (1972). Moral Dilemmas in Medicine, Churchill Livingstone, Edinburgh and London; Fletcher, Joseph (1954), Morals and Medicine, Boston: Beacon Press; and Ramsey, Paul (1970). The Patient as Person. Yale University Press. New Haven.

${ }^{3}$ For an assessment of the problem see McDermott, Walsh (1967), Opening comments on the changing mores of biomedical research. Annals of Internal Medicine, Supplement 7, 39-42, in Katz, op cit, pp 316-318.

4For comment on the vexing issue of the distinction between therapy and research, see 'Responsibility in investigations in human subjects', from the Report of the Medical Research Council, 1962-63, pp 21-25; Feinstein, Alvan R (1974). Medical ethics and the architecture of clinical research, Clinical Pharmacology and Therapeutics, 15, no 3, 316-334; and Committee of the Royal College of Physicians, 'Supervision of the ethics of clinical research investigations in institutions', July, 1973, Appendix B, p 4 .

${ }^{5}$ For examples of focus on special classes of subjects, see Edwards, R G (1974). Fertilization of human eggs in vitro: Morals, ethics and the law, The Quarterly Review of Biology, 49, 3-26; research investigations in adults (1973). British Medical Fournal, 2, 220-224; Severely malformed children (1973), British Medical fournal, 2, 284-289; Research investigations in children (1973), British Medical fournal, 2, 402-407; and Research investigations and the fetus (1973). British Medical Fournal, 2, 464-468.

${ }^{6}$ For the most thorough study of institutional review structures, done from a sociological perspective, see Barber, Bernard, Lally, John J, Makarushka, Julia Loughlin, and Sullivan, Daniel (1973). Research on human subjects. Russell Sage Foundation, New York. For examples of questionable research see Beecher, Henry $K$, Ethics and clinical research (1966). New England fournal of Medicine, 274, 1354-1360; and Pappworth, Morris H (1968). Human Guinea Pigs: Experimentation on Man. Beacon Press; Boston.
${ }^{7}$ Committee, Royal College of Physicians, op cit, p 2.

${ }^{8}$ Monitoring is often seen as desirable, but unworkable. T For two discussions of possibilities, and some $\overrightarrow{\bar{D}}$ examples, see Katz, op cit, pp 919-923, and Katz, Jay, Who is to keep guard over the guards themselves? (1972). Fertility and Sterility, 23, 604-609.

${ }^{9}$ For a good discussion of limitations and problems with드 sanctions and professional review committees, see $\bar{\sigma}$ Veatch, Robert (1972). Medical ethics: professional $\bar{c}$ or universal? Harvard Theological Review, 65, 531559. Veatch surveys a number of cases and indicates how difficult it is to get meaningful sanctions $\infty$ applied. For a very illuminating case study, see $\vec{\circ}$ Katz, op cit, pp 9-67.

${ }^{10}$ See Woodford, F P (1972). Ethical experimentation $\vec{\omega}$ and the editor, New England Fournal of Medicine, 289, 892. Woodford has convened groups of editors $\underset{\mathbb{\Phi}}{\vec{T}}$ in the United States, in Britain, and in Europe to discuss and develop policies on unethical research. But see Ingelfinger, F J (1973). Ethics of experimentation on children, New England fournal of Medicine, 288, 791-2, (12, April 1973). Ingelfinger, editor of the New England Fournal of Medicine, is offering a defence or justification for publishing another report on research growing out of the much publicized Willowbrook case. His editorial and the $\vec{\theta}$ report indicate the problems in developing and $v$ maintaining policy on editorial censorship.

${ }^{11}$ For examples of structures and discussion of problems, see Katz, op cit, pp 886-906.

${ }^{12} \mathrm{~T}$ wo good examples of what to me are limited conceptions of what needs to be considered in an

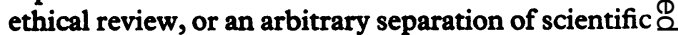
and ethical, are to be found in Research investi- $\overrightarrow{\bar{D}}$ gation in adults, op cit, p 222, and Katz, op cit, p9r r. $\frac{0}{3}$ In the former, Professor $\mathrm{L} J$ Witts comments on ethical committees and says that the main purpose $\frac{F}{0}$ is to give meaning to informed consent. Katz expresses uncertainty as to whether the committee $\overline{\overline{3}}$ should evaluate the design of the experiment.

${ }^{13}$ See Barber, et al (op cit) on the sociological factors 3 that affect group relations and decisions.

${ }^{14}$ For one assessment of positive value of lay members, see Katz, op cit, p 9I I, and comment by Calabresi, 0 $G$, in report of radio discussion.

${ }^{15}$ Consent is one of the most difficult problems in experimentation. It is essential to protect individual integrity in participating in research, but a serious $N$ question is raised about how informed a subject is and whether true consent is given. For some comment on some of the procedural problems and $\tilde{W}$ how the hospital setting and time demands in that setting affect consent, see Bradford, H Gray 'Some Vagaries of Consent', Preliminary, un-

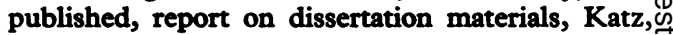
op cit, p 660 . See also Barber, et al, op cit, p I35 and $p$ I 43 on problems of manipulation in obtaining consent.

${ }^{16}$ See Barber, op cit, pp 193-197.

${ }^{17}$ For a probing discussion of the rights of the individual and the rights of society, see Jonas, Hans, Philosophical reflections on experimenting with human? subjects, Daedalus, op cit, pp 219-248. For ano example of the statement that society does have 
some rights vis-a-vis the individual, even in searching for improved methods for controlling disease, see Ingelfinger, op cit.

${ }^{18}$ Gifford, Robert H, and Feinstein, Alvan R (1969). A critique of methodology in studies of anticoagulant therapy for acute myocardial infarction, New England Fournal of Medicine, 280, 351-357.

${ }^{19}$ Chalmers, Thomas C (1967). The ethics of randomization as a decision making technique and the problem of informed consent, Report of Fourteenth Conference of Cardiovascular Training Grant Program Directors, National Heart Institute, Bethesda, Md, USA, DHEW, pp 89-90, in Katz, op cit, pp 377-8.

${ }^{20}$ See Moore, Francis D, Therapeutic innovation: Ethical boundaries in the initial clinical trials of new drugs and surgical procedures, Daedalus, op cit, 502-523.

${ }^{21}$ Shaw, Lawrence $W$, and Chalmers, Thomas C (1970). Ethics in cooperative clinical trials, Annals of the
New York Academy of Sciences, op cit, pp 487-8. ${ }^{22}$ Gifford and Feinstein, op cit.

${ }^{23}$ Strauss, Maurice B (1973). Ethics of experimental therapeutics, New England fournal of Medicine, 288, pp I 183-4, and Rutstein, David D, The ethical design of human experiments, Daedalus, op cit, pp 523-542.

${ }^{24}$ See Shaw and Chalmers, op cit; Rutstein, ibid, Gifford and Feinstein, op cit. For statement on lack of controlled trials in the United Kingdom, see British Medical Fournal, (28 April 1973), op cit.

${ }^{25}$ Chalmers, op cit; Barber et al, op cit; Shaw and Chalmers, op cit.

${ }^{26}$ See Katz, op cit, pp 688-689. For opposite view, see Jonas, op cit.

${ }^{27}$ See Katz, op cit, 685-6, and Jonas, op cit.

${ }^{28}$ See Rutstein, op cit.

${ }^{29}$ See Rutstein, op cit. 